\title{
GAYA PENGURUSAN KONFLIK GURU BESAR
}

\author{
LOKMAN MOHD TAHIR ${ }^{1}$, MOHD ANUAR ABD RAHMAN ${ }^{2} \&$ \\ NORMAH ABD KADIR ${ }^{3}$
}

\begin{abstract}
Abstrak. Konflik merupakan fenomena semulajadi yang dialami oleh setiap individu yang berinteraksi dengan individu lain. Setiap orang mempunyai gaya tersendiri dalam menguruskan konflik mengikut kesesuaian dan keadaan. Maka kajian ini cuba meneliti gaya penyelesaian konflik yang digunakan oleh guru besar menggunakan lima kaedah pengurusan konflik yang dikemukakan dalam model Thomas-Kilmann, iaitu gaya persaingan, kolaborasi, mengelak, akomodasi dan tolak ansur. Populasi kajian adalah 88 orang guru besar sekolah rendah daerah Johor Bahru yang dipilih sebagai responden. Bagi menganalisis dapatan kajian ini, dua jenis statistik yang digunakan, iaitu statistik deskriptif mendapatkan jumlah skor, min dan peratus. Manakala statistik inferensi untuk pengujian hipotesis, iaitu menggunakan Ujian-t dan ANOVA. Analisis deskriptif menunjukkan bahawa min pengurusan konflik adalah gaya kolaborasi yang paling digemari manakala gaya persaingan adalah gaya pengurusan yang paling kurang digemari. Data daripada pengujian hipotesis juga mendapati bahawa tidak terdapat perbezaan yang signifikan di antara faktor jantina, umur, taraf akademik, tempoh perkhidmatan sebagai guru besar dan keterlibatan kursus pengurusan konflik dengan gaya pengurusan konflik guru besar sekolah rendah daerah Johor Bahru.
\end{abstract}

Kata kunci: Guru besar; pengurusan konflik; gaya kolaborasi; gaya akomodasi; gaya bersaing

\begin{abstract}
Conflict is a natural phenomenon faced by every individual in their communication process and interaction with others. Every individual has his/her own way of dealing with conflicts. In this research, consisted of five conflict management styles which were adapted from ThomasKilmann Model i.e competitive conflict management, accommodation, tolerance, collaboration and eluding were assessed. Respondents from this study were 88 head teachers from primary schools in Johor Bahru district. Two main statistics were used which descriptive statistics while inferential statistics were also being in testing the hypotheses. Descriptive analyses indicated that collaboration style was the most popular whereas competitive style was the least popular. The result of hypotheses testing indicated that there were no significant differences between sex, age, marital status, academic educational level and length of service as head of school and with conflict management styles among the heads of primary school studied.
\end{abstract}

Keyword: Head teachers; conflict management; collaboration style; accommodation style; competitive style

\subsection{PENGENALAN}

Pengurusan sekolah pada masa kini amat kompleks kerana menghadapi pelbagai masalah dan konflik dalam kalangan kakitangannya. Dasar Pembangunan Negara 
(DPN) seperti yang termaktub dalam Rangka Rancangan Jangka Panjang Kedua (1991-2000, RRJP 2) menyenaraikan beberapa cabaran yang meliputi aspek politik, sosial, kebudayaan, dan sikap masyarakat Malaysia. Cabaran tersebut memberi implikasi yang besar ke arah membangunkan sistem pendidikan bertaraf dunia. Cabaran utama yang dihadapi oleh sistem pendidikan kebangsaan kini adalah untuk melahirkan warga negara yang berdaya tahan, dinamik, progresif, berilmu pengetahuan, kreatif, inovatif dan berdaya saing pada peringkat negara dan antarabangsa. Pada masa yang sama, sistem pendidikan turut menggariskan usaha bagi meningkatkan nilai-nilai akhlak mulia dan moral, menanamkan sikap positif dan liberal serta mempunyai budaya penyayang dalam kalangan warga Malaysia. Hasrat dan matlamat ini telah diterjemahkan dalam Falsafah Pendidikan Kebangsaan dan Pelan Induk Pembangunan Pendidikan (Pelan Induk Pembangunan Pendidikan 2006-2010).

Konflik adalah masalah dalaman sebuah organisasi sekolah tidak kira di mana lokasi mahupun jenis sekolah. Segelintir masyarakat menganggap konflik merupakan satu pengalaman negatif, iaitu merujuk kepada situasi tegang antara satu pihak dengan pihak yang lain. Misalnya, di sekolah wujud konflik antara pihak pentadbiran dengan guru yang dijangka mampu mengugat produktiviti sesebuah sekolah. Bagi mengatasi masalah yang kronik ini, pengetua atau pentadbir sekolah perlu dan sentiasa berusaha mencari kaedah terbaik bagi menyelesaikan konflik yang berlaku. Ini dibuktikan melalui hasil kajian oleh Thomas dan Schmidth (1972) yang mendapati bahawa seorang pengurus di Amerika Syarikat telah menumpukan kira-kira dua puluh peratus daripada masa kerjanya bagi menyelesaikan masalah konflik yang timbul. Di Malaysia pula, dianggarkan lebih kurang satu setengah daripada lapan jam masa bekerja sehari adalah ditumpukan bagi menghadapi konflik (Jaafar, 1996).

Menurut Steers dan Black (1994), pengkelasan konflik dalam organisasi boleh dibahagikan kepada empat kategori utama, iaitu: konflik matlamat, iaitu konflik yang berlaku apabila kehendak individu dan kumpulan dalam organisasi berbeza dengan kehendak individu dan kumpulan lain. Kedua, konflik kognitif yang timbul apabila pendapat dan idea individu dan kumpulan tertentu bercanggah dengan idea individu atau kumpulan yang lain walaupun mereka berkhidmat dalam organisasi yang sama. Ketiga, konflik afektif yang terjadi apabila sikap dan perasaan individu dan kumpulan tidak bersesuaian dengan individu atau kumpulan yang lain. Keempat, konflik gelagat, iaitu gelagat individu dan kumpulan tidak dapat diterima oleh individu dan kumpulan yang lain. Bagi mengatasi masalah ini, Fasnacht (1990) dan Korabik et al. (1993) menyatakan bahawa pentadbir sekolah perlu bijak mengamalkan kaedah pengurusan konflik kerana kebijaksanaan pentadbir dalam mengamalkan gaya pengurusan konflik, kurang sikap dan tingkah laku pekerja itu adalah penggerak kepada sistem perkembangan dan akan mempengaruhi keberkesanan produktiviti sesebuah organisasi tersebut. Greenberg (1996) pula menyuarakan pandangan bahawa manusia bertanggungjawab ke atas setiap tindakan yang diambilnya 
berdasarkan kepada situasi yang sesuai dan serasi dengannya. Meneliti situasi di sekolah, konflik yang berlaku antara guru dengan guru dan antara guru dengan pihak pentadbir secara tidak langsung telah memberi peluang kepada guru besar untuk memilih gaya, amalan mahupun pendekatan yang sesuai bagi mengatasi konflik dalam organisasi sekolah mereka. Dalam situasi yang lain pula, guru besar selaku pemimpin sekolah perlu tahu kaedah untuk mengatasi dan menguruskan konflik dengan memilih gaya pengurusan konflik yang sesuai dengan jenis, lokasi mahupun budaya sekolah mereka. Konflik yang tidak ditangani dengan baik oleh pemimpin berupaya merosakkan produktiviti, semangat berpasukan malah membantutkan perubahan dalam organisasi.

\subsection{KONFLIK DAN KEPENGETUAAN}

Dalam menuju kecemerlangan organisasi, pemimpin juga perlu bijak menyelesaikan konflik. Secara definisi, konflik atau pertentangan personaliti mungkin timbul akibat tugas yang dipertanggungjawabkan tidak jelas atau bercanggah dari sudut nilai, sikap, keperluan staf dengan hasrat pemimpin (Webb \& Norton 2003). Mengikut Kotter (1985) pula, konflik dalam organisasi wujud kerana perbezaan antara unitunit atau individu akibat pengagihan sumber yang terhad serta perbezaan dari segi nilai dan kepercayaan. Menurut Kotter (1985) lagi, terdapat beberapa faktor dalam organisasi yang menyumbang kepada konflik antaranya adalah saiz organisasi yang kompleks dan besar, teknologi yang pelbagai, persaingan, peraturan, kesatuan sekerja, serta kategori pekerja yang tidak seragam. Bagaimanapun, Pfeffer (1996) pula menegaskan bahawa pemimpin perlu menangani konflik melalui kaedah seperti meraih sokongan daripada pengikut dan pihak luaran, iaitu individu yang berpengaruh adalah penting dalam membuktikan kesahan kekuasaan pemimpin dalam organisasi.

Dalam berbicara tentang kehadiran konflik dalam organisasi, Heffron (1989) juga menyifatkan konflik adalah asas kepada perubahan sosial dalam organisasi yang menjurus ke arah kreativiti dan inovasi. Konflik didapati menggalakkan penggunaan pelbagai idea dan pendekatan dalam penyelesaian masalah. Tanpa konflik, organisasi bersifat statik serta mempunyai masalah untuk berubah. Bagi Heffron (1989) juga, konflik sebenarnya membawa banyak kelebihan jika ia bijak diuruskan dengan cekap oleh pemimpin. Secara asasnya, terdapat tiga jenis konflik, iaitu konflik mendatar, iaitu (antara jabatan), konflik menegak (antara pihak bawahan dengan atasan) dan konflik budaya (antara kumpulan kerana perbezaan nilai). Masalah yang timbul ialah kuasa dan politik sering tidak digunakan pada situasi yang betul oleh pemimpin.

Pfeffer (1996) pernah mencadangkan supaya pemimpin menggunakan kemahiran politik dalam menyelesaikan konflik organisasi, iaitu tujuan perkembangan organisasi. Walaupun konflik mempunyai implikasi negatif terhadap perkembangan organisasi, namun konflik mempunyai kelebihan tersendiri, iaitu ia juga dikatakan menyumbang 
kepada penghasilan budaya persaingan antara satu kumpulan dengan kumpulan yang lain. Budaya persaingan juga didapati menyumbang kepada peningkatan produktiviti kerana adanya unsur 'irihati' dan berusaha untuk menjadi kumpulan yang terbaik. Dalam situasi ini, Jamali (2001) yang pernah melaksanakan kajian perbandingan tentang kaedah pengurusan konflik dalam kalangan pengetua sekolah menengah di Malaysia pula mendapati bahawa budaya kerjasama, semangat berpasukan serta perbincangan secara kolektif dan terbuka yang digelar sebagai 'perkongsian' antara pengetua dan guru adalah kunci utama kepada peningkatan komitmen atau iltizam guru untuk bekerja dengan rajin.

\subsection{PERSOALAN DAN HIPOTESIS KAJIAN}

Berdasarkan kepada permasalahan yang telah dikemukakan, maka penyelidik ingin mengenal pasti gaya pengurusan konflik yang diamalkan oleh guru besar di Johor Bahru dengan merujuk kepada model Kilmann dan Thomas (1978). Penyelidikan tentang gaya pengurusan konflik di kalangan guru besar turut bertujuan untuk menjawab persoalan-persoalan berikut:

(i) Adakah guru besar di Johor Bahru melaksanakan semua lima gaya pengurusan konflik berdasarkan model Thomas dan Kilmann?

(ii) Apakah gaya pengurusan konflik paling digemari oleh guru besar berdasarkan skor min?

(iii) Apakah gaya pengurusan konflik paling tidak digemari oleh guru besar berdasarkan skor min?

(iv) Adakah terdapat perbezaan dalam gaya pengurusan konflik berdasarkan faktor demografi (jantina, umur, kelayakan akademik dan tempoh mentadbir).

Berdasarkan persoalan kajian yang disenaraikan di atas, empat hipotesis telah dibina untuk menjawab persoalan kajian. Hipotesis yang telah dibina adalah:

$\mathrm{H}_{0} 1$ : Tidak terdapat perbezaan yang signifikan amalan gaya pengurusan konflik berdasarkan jantina guru besar.

$\mathrm{H}_{0} 2$ : Tidak terdapat perbezaan yang signifikan dalam gaya pengurusan konflik berdasarkan umur guru besar.

$\mathrm{H}_{0} 3$ : Tidak terdapat perbezaan yang signifikan dalam gaya pengurusan konflik berdasarkan tempoh mentadbir guru besar.

$\mathrm{H}_{0} 4$ : Tidak terdapat perbezaan yang signifikan dalam gaya pengurusan konflik berdasarkan kelulusan akademik guru besar. 


\subsection{METODOLOGI KAJIAN}

Kajian ini dijalankan di semua sekolah rendah daerah Johor Bahru yang merangkumi lapan puluh lapan buah sekolah rendah dalam daerah Johor Bahru, terdiri daripada 71 buah sekolah kebangsaan, 13 buah sekolah jenis kebangsaan Cina dan empat buah jenis kebangsaan Tamil. Maklumat, bilangan dan nama sekolah serta kebenaran lokasi kajian diperolehi daripada Pejabat Pelajaran Daerah Johor Bahru. Responden dalam kajian ini mewakili semua guru besar sekolah rendah daerah Johor Bahru, iaitu seramai 88 orang guru besar yang terlibat dalam memberi maklum balas soal-selidik berkaitan gaya pengurusan konflik. Item soal selidik adalah dibina berdasarkan kepada model Thomas-Kilmann Conflict (1977), iaitu lima gaya utama pengurusan konflik, iaitu: (i) persaingan (ii) kolaborasi (iii) mengelak (iv) akomodasi (v) kompromi. Kajian rintis pula telah dilaksanakan bersama 10 orang guru besar sekolah rendah di daerah Kulai. Hasil kajian rintis mendapati bahawa nilai alfa cronbach untuk instrumen di atas mempunyai indeks koefisien kebolehpercayaan yang baik dengan nilai .808. Maka, dapat dikatakan bahawa instrumen ini sesuai digunakan untuk kajian sebenar tanpa sebarang perubahan. Data-data yang dikumpulkan dan dianalisis melalui analisis kuantitatif merangkumi ciri-ciri demografi seperti umur, jantina, tempoh mentadbir dan taraf pencapaian akademik telah dianalisis dengan menggunakan kaedah kekerapan dan peratusan. Manakala kekerapan, peratusan dan nilai skor min akan digunakan untuk menganalisis gaya pengurusan konflik di kalangan guru besar daerah Johor Bahru. Pengujian hipotesis kajian pula dilaksanakan dengan menggunakan ujian statistik inferensi, iaitu Ujian $\mathrm{F}$, iaitu Ujian yang menggabungkan antara Ujian-t dan ANOVA untuk mencari perbezaan antara faktor demografi guru besar berdasarkan gaya pengurusan konflik.

\subsection{HASIL KAJIAN}

Bahagian ini membincangkan dapatan kajian yang diperolehi mengenai gaya pengurusan konflik dalam kalangan guru besar daerah Johor Bahru. Seramai 89 orang guru besar dari 72 buah sekolah kebangsaan, 13 buah sekolah jenis kebangsaan Cina dan 4 buah sekolah jenis kebangsaan Tamil.

\subsection{Demografi Responden}

Jadual 1 menunjukkan bahawa responden kajian adalah terdiri daripada 33 orang guru besar lelaki yang mewakili 37.5 peratus dan 55 orang guru besar perempuan mewakili 62.5 peratus keseluruhan bilangan guru besar daerah Johor Bahru. Dapatan kajian ini membuktikan bahawa guru besar perempuan adalah lebih ramai daripada guru besar lelaki dalam daerah Johor Bahru. Analisis demografi mengikut umur pula menunjukkan bahawa hanya terdapat dua orang guru besar yang berumur 41 tahun hingga 45 tahun, iaitu sebanyak 2.3 peratus daripada keseluruhan responden 
Jadual 1 Analisis demografi responden

\begin{tabular}{lcc}
\hline Pemboleh ubah & Frekuensi & Peratus \\
\hline Jantina & & \\
Lelaki & 33 & 37.5 \\
Perempuan & 55 & 62.5 \\
Umur & & \\
41 - 45 tahun & 2 & 2.3 \\
46 - 50 tahun & 26 & 29.5 \\
Lebih 50 tahun & 60 & 68.2 \\
Etnik & & \\
Melayu & 68 & 77.3 \\
Cina & 16 & 18.2 \\
India & 4 & 4.5 \\
Kelulusan Akademik & & \\
SPM/MCE & 27 & 30.7 \\
STP/HSC/STPM & 34 & 38.6 \\
Diploma & 20 & 22.7 \\
Ijazah & 7 & 8.0 \\
Tempoh Sebagai Guru Besar & & \\
Lebih 5 Tahun & 36 & 40.9 \\
5 - 10 tahun & 18 & 20.5 \\
Lebih 10 tahun & 34 & 38.6 \\
\hline
\end{tabular}

manakala guru besar yang berumur 46 hingga 50 tahun, iaitu seramai 26 orang, iaitu sebanyak 29.5 peratus daripada keseluruhan responden kajian. Penganalisisan demografi juga menunjukkan bahawa guru besar yang berumur melebihi 51 tahun adalah bilangan paling ramai, iaitu 60 orang, iaitu sebanyak 68.2 peratus daripada keseluruhan responden. Dapatan kajian menunjukkan bahawa guru besar daerah Johor Bahru majoritinya adalah berumur melebihi 51 tahun yang mewakili 68.2 peratus daripada keseluruhan populasi kajian. Ternyata tiada seorang pun guru besar daerah Johor Bahru yang umurnya di bawah 40 tahun. Berdasarkan 88 orang guru besar daerah Johor Bahru, etnik Melayu menunjukkan jumlah yang paling tinggi seramai 68 orang (77.3 peratus) manakala bangsa Cina seramai 16 orang (18.2 peratus) dan India menunjukkan seramai 4 orang (4.5 peratus). Dapatan kajian menunjukkan bahawa etnik Melayu adalah lebih ramai menjadi guru besar sekolah rendah di daerah Johor Bahru sebanyak 77.3 peratus sementara etnik bukan Melayu mewakili 22.7 peratus daripada keseluruhan populasi kajian.

Jadual 1 juga menunjukkan bahawa guru besar sekolah rendah dalam daerah Johor Bahru yang rata-ratanya berkelulusan Sijil Pelajaran Malaysia/Malaysian Certificate Education adalah seramai 27 orang (30.7 peratus). Guru besar yang berkhidmat di Johor Bahru mempunyai kelulusan Sijil Tinggi Persekolahan/Higher School Certificate/Sijil Tinggi Persekolahan Malaysia seramai 34 orang (38.6 peratus). 
Guru besar yang berkelulusan diploma pula adalah [seramai 20 orang (22.7 peratus)]. Kajian juga menunjukkan bahawa terdapat guru besar yang berkhidmat di daerah Johor Bahru mempunyai berkelulusan ijazah, iaitu seramai 7 orang (8 peratus) daripada keseluruhan responden. Dapatan kajian juga menunjukkan bahawa guru besar yang telah berkhidmat sebagai guru besar kurang daripada 5 tahun adalah seramai 36 orang (40.9 peratus), ini diikuti dengan bilangan guru besar yang mempunyai tempoh perkhidmatan antara 5 hingga 10 tahun seramai 18 orang (20.5 peratus). Sementara itu, majoriti guru besar di daerah Johor Bahru didapati telah berkhidmat melebihi 10 tahun seramai 34 orang (38.6 peratus) daripada keseluruhan populasi kajian. Akhir sekali, hasil kajian juga menunjukkan bahawa majoriti guru besar di Johor Bahru didapati tidak pernah mengikuti sebarang kursus berkaitan pengurusan konflik, iaitu seramai 65 orang (73.9 peratus) manakala seramai 23 orang (26.1 peratus) sahaja yang pernah mengikuti kursus pengurusan konflik anjuran Institut Aminuddin Baki dan Jabatan Pelajaran Negeri Johor.

\subsection{Dapatan Kajian}

Perbincangan tentang persoalan kajian (a) dan (b) adalah merujuk kepada Jadual 2 dan Rajah 1 di bawah.

Jadual 2 Skor min lima gaya pengurusan konflik

\begin{tabular}{cc}
\hline Gaya Pengurusan Konflik & Nilai Skor Min \\
\hline Gaya kolaborasi & 4.06 \\
Gaya kompromi & 3.91 \\
Gaya mengelak & 3.69 \\
Gaya akomodasi & 3.60 \\
Gaya persaingan & 3.44 \\
\hline
\end{tabular}

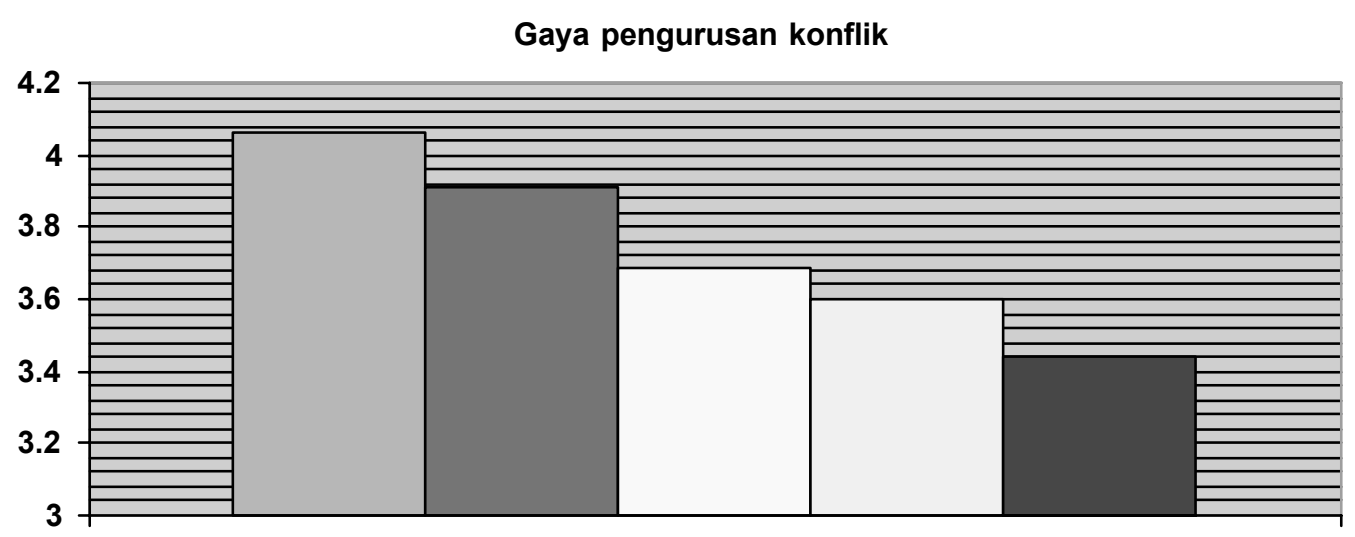

Gaya kolaborasi kompromi mengelak akomodasi persaingan

Rajah 1 Nilai skor min gaya pengurusan konflik guru besar 
Jadual 2 dan Rajah 1 di atas menunjukkan bahawa majoriti guru besar yang berkhidmat di Johor Bahru telah menggunakan kelima-lima gaya pengurusan konflik dalam pengurusannya dalam usaha mereka menangani konflik di sekolah. Dapatan kajian membuktikan bahawa gaya pengurusan konflik yang paling digemari adalah gaya kolaborasi dengan purata nilai skor min yang paling tinggi, iaitu nilai 4.06, diikuti kedua bagi gaya tolak ansur dengan purata nilai skor min 3.91 dan ketiga bagi gaya mengelak dengan purata nilai purata skor min 3.69. Sementara itu, skor min untuk gaya akomodasi pula adalah pada nilai 3.60 dan akhir sekali gaya persaingan dengan purata nilai skor min 3.44 adalah gaya yang paling mempunyai nilai skor min yang paling rendah. Berdasarkan nilai skor min di atas, dapat dikatakan bahawa gaya kolaborasi yang mempunyai purata nilai skor min tertinggi dengan nilai 4.06 adalah gaya pengurusan konflik yang paling digemari oleh guru besar daerah Johor Bahru ketika memimpin dan menguruskan konflik di sekolah.

Bagi menjawab soalan kajian 3, Jadual 2 dan Rajah 1 sekali lagi dirujuk dan didapati bahawa bahawa gaya persaingan mempunyai nilai skor min yang paling rendah sekali di antara empat gaya pengurusan konflik yang lain dengan nilai skor min 3.44. Maka dapatlah dikatakan di sini bahawa gaya persaingan adalah gaya yang paling tidak digemari oleh guru besar sekolah rendah di daerah Johor Bahru ketika menguruskan konflik.

\subsection{Analisis Hipotesis Kajian}

Perbincangan tentang hipotesis kajian cuba meneliti sejauhmana terdapat perbezaan antara amalan dalam gaya pengurusan konflik berdasarkan faktor demografi, iaitu jantina, umur, kelulusan akademik dan tempoh mentadbir guru besar, iaitu bagi menjawab persoalan kajian empat. Bagi menjawab persoalan tersebut, Jadual 3 hingga dirujuk bagi menjelaskan perbezaan amalan pengurusan konflik guru besar berdasarkan faktor demografi mereka.

Jadual 3 menunjukkan nilai $\mathrm{F}$, iaitu perbezaan amalan pengurusan konflik berdasarkan kepada faktor demografi dengan gaya pengurusan konflik guru besar sekolah rendah daerah Johor Bahru. Melalui Ujian F, Nilai F bagi jantina diperolehi melalui Ujian-t manakala Analisis Varians (ANOVA) digunakan bagi menganalisis perbezaan daripada umur, tempoh perkhidmatan menjadi guru besar dan kelulusan akademik.

Hasil kajian menunjukkan bahawa tidak terdapat perbezaan dalam gaya pengurusan konflik berdasarkan kepada semua faktor demografi guru besar, iaitu faktor jantina, kelulusan akademik, tempoh mentadbir guru besar dan umur, iaitu $\mathrm{H}_{0} 1$ hingga $\mathrm{H}_{0} 4$ adalah diterima, iaitu tidak terdapat perbezaan antara amalan pengurusan konflik guru besar di Johor Bahru berdasarkan ciri latar belakang/ demografi mereka. Bagaimanapun, pengecualian diberikan kepada gaya akomodasi, iaitu dengan nilai $\mathrm{F}$ (4.194) dan signifikan (0.018) di mana terdapat perbezaan yang signifikan dalam gaya pengurusan konflik guru besar. Oleh itu, $\mathrm{H}_{0} 3$ adalah ditolak 
Jadual 3 Ujian F bagi faktor demografi guru besar Johor Bahru

\begin{tabular}{lccccc}
\hline $\begin{array}{l}\text { Faktor } \\
\text { Demografi }\end{array}$ & $\begin{array}{c}\text { Gaya } \\
\text { Akomodasi }\end{array}$ & $\begin{array}{c}\text { Gaya } \\
\text { Mengelak }\end{array}$ & $\begin{array}{c}\text { Gaya } \\
\text { Kompromi }\end{array}$ & $\begin{array}{c}\text { Gaya } \\
\text { Persaingan }\end{array}$ & $\begin{array}{c}\text { Gaya } \\
\text { Kolaborasi }\end{array}$ \\
\hline Jantina & & & & & \\
Nilai F & 0.075 & 0.257 & 1.215 & 0.196 & 0.088 \\
Sig & 0.612 & 0.366 & 0.848 & 0.719 & 0.439 \\
Umur & & & & & \\
Nilai F & 0.065 & 0.253 & 0.563 & 2.140 & 0.367 \\
Sig & 0.938 & 0.777 & 0.572 & 0.124 & 0.694 \\
Tempoh Guru Besar & & & & & \\
Nilai F & 4.194 & 0.918 & 1.603 & 0.234 & 1.697 \\
Sig & $0.018^{*}$ & 0.403 & 0.207 & 0.792 & 0.189 \\
Kelulusan Akademik & & & & & \\
Nilai F & 0.385 & 1.349 & 0.858 & 1.776 & 0.978 \\
Sig & 0.764 & 0.264 & 0.466 & 0.158 & 0.407 \\
\hline
\end{tabular}

${ }^{*}$ Nilai Signifikan pada aras $\infty-.05$

untuk amalan penguruan konflik dalam gaya akomodasi, iaitu terdapat perbezaan dalam amalan pengurusan konflik antara guru besar yang baru mentadbir sekolah dengan guru besar yang telah berpengalaman melebihi 5 tahun.

\subsection{RUMUSAN DAN PERBINCANGAN}

Situasi konflik yang berlaku di sekolah akan memberi peluang kepada guru besar untuk memilih gaya bertindak balas terhadap konflik yang mereka hadapi. Kesedaran diri dan pengetahuan dalam bidang pengurusan konflik sedikit sebanyak dapat membantu guru besar mentadbir sekolah dalam keadaan kondusif, mesra pelanggan dan meningkatkan hubungan komunikasi. Kajian tentang amalan pengurusan konflik guru besar ini telah dijalankan untuk dalam kalangan guru besar sekolah rendah daerah Johor Bahru. Selain daripada itu, kajian ini juga cuba untuk mengenal pasti gaya pengurusan konflik yang paling digemari dan tidak digemari oleh guru besar. Dalam kajian ini juga dapat membuktikan sama ada terdapat perbezaan faktor demografi dengan gaya pengurusan konflik dalam kalangan guru besar sekolah rendah daerah Johor Bahru.

Guru Besar yang peka kepada masalah atau konflik di sekolah akan sentiasa memastikan stafnya dapat bekerja secara produktif serta sentiasa cuba menghindarkan gejala-gejala yang menyumbang kepada konflik supaya matlamat organisasi dapat dicapai. Maka sebagai pemimpin sekolah, guru besar sememangnya terpaksa menghadapi konflik yang mudah berlaku dalam persekitaran dan budaya sekolah seperti sikap guru, kerenah ibu bapa malah hubungan yang tidak mesra dalam organisasi sekolah itu sendiri. Dalam konteks ini, kebijaksanaan guru besar amat penting ketika memilih strategi atau amalan terbaik bagi mengatasi masalah ini supaya 
matlamat sekolah dapat direalisasikan. Secara keseluruhan, analisis deskriptif tentang gaya pengurusan konflik menunjukkan bahawa guru besar di Johor Bahru telah melaksanakan kelima-lima gaya pengurusan konflik berdasarkan model Thomas dan Kilmann (1977), iaitu gaya kompromi, gaya akomodasi, gaya bersaing, gaya mengelak dan gaya kolaborasi. Penggunaan kelima-lima gaya pengurusan konflik bagi menangani konflik secara tidak langsung menggambarkan keinginan guru besar untuk bekerjasama dan mewujudkan perhubungan yang harmonis dalam organisasi di samping cuba merealisasikan matlamat sekolah agar mereka memuaskan hati semua pihak sama ada guru, pelajar mahupun ibu bapa. Melalui amalan lima pengurusan konflik, budaya sekolah yang kolaboratif mudah dipupuk serta mampu menjurus kepada pembentukan sekolah yang cemerlang.

Hasil kajian turut membuktikan bahawa guru besar di Johor Bahru lebih cenderung memilih gaya kolaborasi sebagai pilihan utama untuk menangani konflik di sekolah, diikuti oleh gaya tolak ansur, gaya mengelak, gaya akomodasi dan akhir sekali adalah gaya persaingan. Pemilihan gaya kolaborasi sebagai gaya pengurusan konflik yang utama sebenarnya memberi gambaran akan hasrat guru besar untuk memberi peluang kepada kedua-dua pihak yang berkonflik bertemu dan berbincang secara muzakarah dalam inisiatif mencari kata sepakat serta menyelesaikan konflik di sekolah. Secara tidak langsung, gaya kolaborasi ini adalah dianggap sebagai gaya penyelesaian konflik yang menjurus kepada budaya "menang-menang" dalam penyelesaian masalah. Antara andaian asas mengapa guru besar memilih gaya pengurusan kolaborasi adalah bagi mewujudkan semangat berpasukan, budaya bekerjasama dan amalan membantu agar matlamat sekolah dapat dikecapi dengan mudah. Di samping itu, amalan gaya kolaborasi juga mampu mengekalkan hubungan multilateral dan harmonis antara dua pihak yang mudah berkonflik, iaitu antara guru dengan guru serta hubungan antara guru yang pentadbir. Melalui gaya kolaborasi juga, ia mampu meningkatkan tahap kepercayaan antara warga sekolah, membina budaya perkongsian tanggungjawab, memupuk keinginan untuk berubah malah menghormati pandangan dan idea daripada rakan guru yang lain. Kesimpulannya, gaya kolaborasi membawa kaedah penyelesaian yang terbaik dengan menggabungkan pemikiran setiap individu dalam suasana yang harmonis di sekolah serta menjurus kepada peningkatan prestasi guru dan juga produktiviti dalam jangka masa panjang.

Hasil kajian juga mendapati gaya bersaing adalah gaya yang paling tidak digemari oleh guru besar sekolah rendah di Johor Bahru. Gaya bersaing menjadi gaya yang tidak digemari oleh guru besar kerana melalui amalan gaya bersaing ini, kedua-dua pihak yang berkonflik akan sedaya upaya cuba untuk bersaing di antara satu sama lain. Dalam konteks ini, guru besar terpaksa menolak gaya bersaing kerana mereka berpendapat gaya bersaing ini tidak akan menyelesaikan konflik yang berlaku di sekolah malah menjadikannya lebih tegang dan 'parah'. Di samping itu, guru besar juga berpendapat bahawa gaya bersaing ini tidak sesuai dilaksanakan di sekolah 
kerana ia bertentangan dengan asas pembentukan modal insan dan dasar sekolah penyayang.

Berdasarkan ujian hipotesis nul, iaitu $\mathrm{H}_{0} 1$ hingga $\mathrm{H}_{0} 4$, kajian mendapati bahawa tidak terdapat perbezaan yang signifikan dalam gaya pengurusan konflik berdasarkan ciri demografi iaitu jantina, umur, kelulusan akademik dan tempoh mentadbir menjadi guru besar dalam kalangan guru besar. Secara keseluruhan, hasil kajian ini menunjukkan bahawa faktor demografi tidak mempunyai pengaruh yang besar terhadap pemilihan gaya pengurusan konflik dalam kalangan guru besar khususnya guru besar yang berkhidmat di Johor Bahru. Maka, dapat disimpulkan di sini bahawa gaya pengurusan konflik yang diamalkan oleh guru besar di Johor Bahru tidak menunjukkan perbezaan daripada aspek demografi atau ciri latar belakang.

\subsection{KESIMPULAN}

Secara keseluruhan, kajian ini didapati telah berjaya mengenal pasti gaya pengurusan konflik yang dilaksanakan oleh guru besar sekolah rendah yang mentadbir di daerah Johor Bahru. Sebagai rumusan, dapatlah dikatakan bahawa guru besar di Johor Bahru telah memilih gaya kolaborasi sebagai gaya pengurusan konflik utama dalam menyelesaikan masalah konflik di sekolah masing-masing. Secara umum, gaya pengurusan konflik dapat dikategorikan sebagai gaya pengurusan konflik yang mampu membentuk pola komunikasi yang positif di sekolah di samping mampu membentuk budaya sekolah yang lebih penyayang dan harmonis agar setiap warga sekolah dapat berkhidmat dengan lebih efektif dan komited.

\section{RUJUKAN}

Amran Saman. 1993. Pengurusan Konflik: Satu Kajian Kes ke atas Kakitangan Perbadanan Kemajuan Negeri Selangor. Latihan Ilmiah Sarjana Muda. Universiti Kebangsaan Malaysia.

Berry, B. 1995. An Analysis of the Relationship Between Gender and Interpersonal Conflict Management Style of Selected School Administrators. PhD Dissertation. University of Saint Louis.

Brown, L. 1983. Managing Conflict at Organizational Interfaces. Boston: Addison-Wesley.

Condiffe, P. 1995. Conflict Management: A Practical Guide. Kuala Lumpur: Abdul Majeed Co.

Daft, R. 2000. Management. New York: The Dryden Press.

Daft, R. dan A. Raymond. 2001. Organizational Behaviour. New Jersey: Thomson Learning.

Deutsch, M. 1991. Subjective Features of Conflict Resolution: Psychological, Social and Cultural Influences.

Donovan, M. 1993. Academic Deans and Conflict Management. PhD Dissertation. University of Marquette.

Earnest, G. 1992. Conflict Management Styles as Reflection of Jungian Personality Type Preferences of the Cooperative Extension's North Central Region Directions and District Directors. PhD Dissertation. Ohio State University.

Figueroa, D. 1995. Sex and Gender Differences in Interpersonal Conflict Management Behavior in an Academic and Commercial Research Setting. PhD Dissertation. Temple University.

Greenberg, J. 1996. Managing Behavior in Organizations. New Jersey: Prentice Hall.

Greenberg, K. 1980. The Happy Worker: An Analysis of Education and Occupational Difference in Determinants of Job Satisfaction. American Journal of Sociology. 86: 247-271.

Haszminy Mat. 1999. Pengurusan Konflik di Kalangan Pendidik Sekolah Menengah Kebangsaan Daerah Pasir Mas, Kelantan. Sarjana Sains Pengurusan, Universiti Utara Malaysia.

Henkin, A. 2000. Conflict Management Strategies of Principals in Site-Based Managed Schools. Educational Administration. 2: 142-158. 
Jamali Basri. 2001. Pengurusan Konflik di Sekolah Menengah: Satu Kajian Kes. Tesis Ijazah Doktor Falsafah. Universiti Kebangsaan Malaysia.

Johnson, M.1989. Assertiveness and Cooperativeness as Predictors of Interpersonal Conflict Management Behavior. PhD Dissertation. Emory University.

Kilmann, R. dan K. Thomas. 1977. Deveoping a Forced-Choice Measure of Conflict-Handling Behavior. The MODE Instrument. Educational and Psychological Measurement. 37: 309-3225.

Kolbo, D. dan L. Putnam. 1992. The Multiple Faces of Conflict in Organzations. Journal of Organizational Behavior.13: 311-324.

Kotter, J. 1988. Power and Influence: Beyond Formal Authority. New York: Free Press.

Lamberton, L. dan M. 2002. Human Relations: Strategies for Success. New York: McGraw Hill.

Manimaran a/ Parasuraman.1992. Penyelesaian Konflik Dalam Organisasi. Latihan Ilmiah Sarjana Muda. Universiti Kebangsaan Malaysia.

Md. Yadi Said. 2006. Mengurus Konflik. Kuala Lumpur: PTS.

Meyers, R.1994. Conflict Management Style and Burnout of Missionaries. PhD Dissertations. George Fox College.

$\mathrm{Ng}$ Li Kiang. 1999. Hubungan antara Gaya Kepimpinan Penyelia dengan Kaedah Penyelesaian Konflik dari Persepsi Operator Pengeluaran: Satu Kajian Kes di Syarikat Steel Centre (M) Sdn. Bhd. Senai, Johor. Ijazah Sarjana Muda Pengurusan Teknologi: Universiti Teknologi Malaysia.

Ng Yue Fung. 2000. Persepsi Pekerja Terhadap Pengurusan Konflik di Tempat Kerja: Satu Kajian di Prestige Packages Sendirian Berhad (PPSB). Projek Sarjana Muda Sains Pembangunan Sumber Manusia: Universiti Teknologi Malaysia.

Nozri Senawi. 1994. Cara Penyelesaian Konflik: Perbandingan antara Orang Melayu Perlis dengan Melayu Thailand. Latihan Ilmiah: Universiti Kebangsaan Malaysia.

Olorunsala, R. 1997. The Anatomy and Management of Staff Conflicts in A Nigerian University Library. Library Management. 7: 328-334.

Pepper, G. 1995. Communicating in Organizational: A Culture Approach. New Jersey: McGraw-Hill.

Pfeffer, J. 1996. Managing with Power: Politics and Influence in Organizations. Boston: Harvard Business School Press.

Rahim, M. 1983. Rahim Organizational Inventory. Palo Alto, CA: Consulting Psychologists.

Rahim, M. 1992. Managing Conflict in Organizations. Westport, CT: Prager.

Razali Mat Zin. 1993. Kepimpinan dalam Pengurusan. Kuala Lumpur: Utusan.

Richardson, J. 1995. Avoidance as an Active Mode of Conflict Resolution. Team Performance Management. 01: 19-25.

Robbins, S. dan D. Decenzo. 2001. Fundamentals of Management, New Jersey: Prentice Hall.

Sabitha Marican dan Mahmood Nazar. 1995. Hubungan Manusia dalam Organisasi. Kuala Lumpur: Utusan Publications \& Distributors Sdn. Bhd.

Schermerhon, J. 1995. Basic Organizational Behavior. New York: John Wiley.

Schmidt, S. dan T. Kochan. 1972. Conflict Towards Conceptual Clarity. Administrative Scince Quarterly. 17: 359370 .

Schneer, J. 1987. Manifest Need as Personality Predispositions to Conflict-Handling Behavior. Human Relations: 40(9): 575-590.

Siew Pei Hwa. 1996. Etnik, Dimensi Budaya, Dimensi Personaliti, Kedudukan Pangkat dan Cara Menangani Konflik di Kalangan Anggota TLDM: Satu Kajian di Pangkalan TLDM Lumut Perak. Latihan Ilmiah Muda Universiti Kebangsaan Malaysia.

Steers R. dan J. Black. 1994. Organizational Behavior. New York: Harper Collins.

Tai Li Chean. 1993. Personaliti, Situasi Konflik dan Cara Penyelesaian Konflik: Satu Tinjauan di Kalangan Anggota Bukan Tempur Tentera Darat Malaysia. Latihan Ilmiah: Universiti Kebangsaan Malaysia.

Tan Hong Lee. 1997. A Comparative Study of Interpersonal Conflict Resolution Styles Between Malaysian and Japanese Managers. Projek Sarjana Muda: Universiti Sains Malaysia.

Tan Lee Choo. 1994. Perbezaan Jantina dalam Gaya Penyelesaian Konflik di Kalangan Eksekutif. Projek Sarjana Muda: Universiti Kebangsaan Malaysia.

Turin Ahmad. 1995. Gaya Pengurusan Konflik di Kalangan Guru-guru Sekolah Menengah Daerah Kota Setar, Kedah Darul Aman. Tesis Sarjana Pengurusan. Universiti Utara Malaysia.

Ungku Norulkamar Ungku Ahmad. 2002. Tabiat Organisasi Satu Dimensi Global. Selangor: Pearson. 
Wan Mohd Zahid Mohd. Nordin. 1993. Persidangan Pendidikan Nasional. Pengisian Wawasan Pendidikan. Kementerian Pendidikan Malaysia. Institut Aminuddin Baki.

Wan Izzudin. 1991. Strategi Membina Pasukan Berkesan. Kuala Lumpur: Nurin Enterprise.

Webb, L. dan M. Norton. 2003. Human Reseource Administration: Personnel Issues and Needs in Education. New Jersey: Prentice Hall.

Whetten D. dan K. Cameron. 1991. Developing Management Skills. New York: Harper Collins.

Zainuddin Zakaria. 2006. Komunikasi Efektif. Kuala Lumpur: PTS

Zairana Ishak. 1998. Cara Gaya Pengurusan Konflik di Kalangan Pekerja daripada Pelbagai Etnik, Taraf Pendidikan, Tahap Umur dan Pengalaman Kerja. Latihan Ilmiah: Universiti Kebangsaan Malaysia. 